http://dx.doi.org/10.30681/23588403v12i03196218

\title{
UMA ANÁLISE DA CONCEPÇÃO DE LEITURA NOS DOCUMENTOS OFICIAIS PARA O ENSINO MÉDIO EM ALAGOAS
}

\author{
Cristiano Lessa de OLIVEIRA (IFAL) ${ }^{1}$ \\ Neilton Farias LINS (IFAL) ${ }^{2}$ \\ Data de recebimento: 07/10//2019 \\ Aceite: 16/11/2019
}

\begin{abstract}
Resumo: O objetivo deste trabalho é estabelecer a relação existente entre situações propostas nos itens de leitura da avaliação do Ensino Médio no Estado de Alagoas, o Aprendizagem da Rede Estadual de Ensino de Alagoas (doravante AREAL), e o Referencial Curricular de Língua Portuguesa da Rede Estadual de Ensino de Alagoas (doravante RECREAL). Os teóricos que dão luz a esta pesquisa, em especial a concepção de leitura, são (KOCH, 2014; JOUVE, 2002; THÉRIEN, 1990; BOURDIEU E CHARTIER, 2011; SILVEIRA E OLIVEIRA, 2015; MARCUSCHI, 1996; 2008); sobre o prisma da literatura que trata da leitura, trabalhamos com (KOCH, 1997, 1989, 2006; PRESTES, 2000; ELIAS, 2011; GERALDI, 1985; BATISTA, 2016; RONCARATI, 2010; SOLÉ, 1988; TERZI, 2002, ZILBERMAN \& SILVA, 2002). Ademais, verificam-se também as bases teórico-metodológicas do AREAL e do RECREAL, no que se refere à concepção de leitura subjacente tanto ao teste quanto ao referencial; o respectivo estudo efetiva-se por meio de uma análise documental, que se divide em duas partes: primeiro, são estudados os relatórios do AREAL e RECREAL para identificar as concepções neles presentes; posteriormente, são analisados todos os itens de leitura disponibilizados. Os resultados prévios, apontados nos documentos em análise, constataram que a concepção defendida por esses documentos oficiais não prevê, em sua íntegra, a leitura fora do ambiente escolar. A tônica do trabalho com a leitura se volta, especialmente, para o locus escolar. Daí, a necessidade de a Rede desenvolver uma concepção sociointeracionista de leitura que se volte a práticas sociais fora do ambiente escolar.

Palavras-chave: Leitura. Concepção de leitura. Texto.
\end{abstract}

Resumen: El objetivo de este trabajo es establecer la relación entre las situaciones propuestas en los ítems de lectura de la evaluación de la escuela secundaria en el estado de Alagoas, el "Aprendizagem da Rede Estadual de Ensino de Alagoas" (AREAL) y el "Referencial Curricular de Língua Portuguesa da Rede Estadual de Ensino de Alagoas" (RECREAL). Los teóricos que dan luz a esta investigación, especialmente la concepción de lectura, son (KOCH, 2014; JOUVE, 2002; THÉRIEN, 1990; BOURDIEU Y CHARTIER, 2011; SILVEIRA Y OLIVEIRA, 2015; MARCUSCHI, 1996 ; 2008); sobre el prisma de la literatura que trata sobre la lectura, trabajamos con $(\mathrm{KOCH}, 1997,1989,2006$; PRESTES, 2000; ELIAS, 2011; GERALDI, 1985; BATISTA, 2016; RONCARATI, 2010; SOLÉ, 1988; TERZI, 2002, ZILBERMAN \& SILVA, 2002). Además, también se verifican las bases teóricas y metodológicas de AREAL y RECREAL, con respecto a la concepción de lectura que subyace tanto al test como al referencial; el estudio se realiza mediante un análisis documental, que se divide en dos partes: primero, se estudian los informes de AREAL y RECREAL para identificar los conceptos presentes en ellos; Posteriormente, se analizan todos los elementos de lectura disponibles. Los resultados anteriores, señalados en los documentos bajo análisis, verificaron que la concepción defendida por estos documentos oficiales no proporciona, en su totalidad, la lectura fuera del entorno escolar. El enfoque del trabajo de lectura se centra especialmente en el locus de la escuela. De ahí la necesidad de que la Red desarrolle una concepción social interaccionista de lectura que se centre en las prácticas sociales fuera del entorno escolar.

\footnotetext{
${ }^{1}$ Doutor em Linguística pela Universidade Federal de Alagoas (UFAL) e Prof. Portuguesa e Espanhol do Instituto Federal de Alagoas (IFAL)

${ }^{2}$ Mestre em Linguística pela Universidade Federal de Alagoas (UFAL) e Prof. Língua Portuguesa do Instituto Federal de Alagoas (IFAL)
} 


\section{Revista de Estudos Acadêmicos de Letras}

Palabras Clave: Lectura. Concepción de lectura. Texto.

\section{INTRODUÇÃO}

Garantir que o ensino da leitura e da escrita aos alunos seja uma das principais tarefas da escola constitui-se um discurso assegurado por diversos especialistas no ensino da língua. Dessa afirmação surge o principal questionamento: Por que as tarefas de ler e escrever precisam ser postas como centro de todo o fazer escolar? De tal inquirição, tem-se que tanto a leitura como a escrita são extremamente fundamentais, uma vez que levam as pessoas a exercerem seus deveres, exigirem seus direitos, trabalharem, participarem de forma cidadã da sociedade, bem como, informarem-se e aprenderem ao longo da vida.

Tudo isso não se constitui algo tão efêmero que a escola seja capaz de dar conta, de fazer cumprir essa obrigação, no que diz respeito às atividades de leitura e de escrita. Um dos primeiros passos seria garantir que os alunos não apenas tenham, mas mantenham contato com os diversos gêneros textuais, não só isso, assim como se constitui fundamentalmente importante tornar regular o uso dos respectivos gêneros no cotidiano dos discentes. Para tanto, convém a criação de uma dinâmica de trabalhos com tais gêneros no dia a dia desses alunos, de forma multifacetada, além do que, é claro, cabe em especial, o incentivo do professor na construção de um dia a dia em sala de aula voltado para as práticas de leitura e de escrita.

Nesse aspecto, há de se enfatizar que o papel da leitura e da escrita é fundamentalmente importante para o aprendizado dos demais teores escolares. Isso corrobora com Cagliari (2009, p. 130), o qual afirma que "O melhor que a escola pode oferecer aos alunos deve estar voltado para leitura. Se um aluno não se sair muito bem nas outras atividades e for um bom leitor, penso que a escola cumpriu sua tarefa". Logo, cabe ênfase no desenvolvimento da compreensão leitora, assim como da escrita pelo discente, fundamentada nas práticas escolares. Tal responsabilidade, em desenvolver a competência comunicativa dos discentes, precisa e deve ser um dos principais compromissos assumidos pela escola. O referido autor (2009, p. 130) discorre ainda que "se, porém, o aluno tiver notas excelentes em tudo, mas não se tornar um bom leitor, sua formação será profundamente defeituosa e ele terá menos chance no futuro do que aquele que, apesar das reprovações, se tornou um bom leitor”.

Embora comumente, o discurso oficial apresente uma defesa de ponto de vista que define que ler e escrever são atividades essenciais. Programas de avaliação no Ensino Fundamental, como é o caso do SAEB e o Programa Internacional de Avaliação de Alunos 


\section{Revista de Estudos Acadêmicos de Letras}

(PISA) e no Exame Nacional Ensino Médio (doravante ENEM) demonstram a presença de vulnerabilidades na escola, no que se refere à execução dessas atividades. Os exames pátrios explicitam, por exemplo, que um grande índice de aprendizes não possui a compreensão do código convencional da leitura e da escrita.

No Pisa realizado em 2015, 51,0\% dos estudantes ficaram abaixo do nível 2 de proficiência. Segundo o Relatório do PISA em 2015, "patamar que a OCDE estabelece como necessário para que o estudante possa exercer plenamente sua cidadania" Segundo o mesmo Relatório, o estado de Alagoas está com a pior colocação alcançada na avaliação de leitura, compreendendo como média geral, a pontuação de 362 pontos. A média de desempenho do país foi de 407 pontos. É a segunda queda consecutiva na área de leitura desde 2009. O exame demonstrou que esses alunos são capazes apenas de "localizar informações explícitas em um texto ou reconhecer o tema principal". Isso corrobora a ideia de que, tais educandos não são capazes de "fazer inferência", de "estabelecer relações entre textos" ou de "demonstrar uma compreensão global e detalhada de um texto com conteúdo ou forma não familiar", elementos primordiais na compreensão de texto ou para proficiência leitora. Esses dados levam à dedução de que tal problemática vai acompanhar esse aluno em todo o Ensino Médio, seja ele regular ou técnico-profissionalizante. Isso é inferido porque há de se enfatizar que a aplicação do PISA é feita com alunos de 15 anos, que no geral, devem ou deveriam estar cursando o $9^{\circ}$ ano do Fundamental.

É perceptível que, embora o Ensino Fundamental tenha se expandido de forma contundente, e a "democratização" da educação tenha alcançado patamares não vistos ainda, em detrimento da qualidade do que se tem democratizado, apesar de que não nos ateremos ao mérito da questão, visto não ser esse o objeto de análise neste trabalho, faz-se necessário destacar que a educação brasileira passa por uma diversidade de problemas, a exemplo da evasão, da retenção de ano letivo e da sua má qualidade. Tais problemáticas refletem de forma decisiva nos sofríveis resultados obtidos pelos estudantes brasileiros nos exames que testam sua compreensão leitora, o que vai se prolongar para o Ensino Médio.

Se considerarmos que o Brasil ocupa uma posição de estigma em relação aos resultados nos exames que medem o grau de compreensão leitora, mesmo assim, cabe destacar que há uma inquietação manifesta em relação a esse problema. Isso leva a questionamentos importantes a esse respeito, apesar de que, esse trabalho não tenha intenção de pesquisar e responder a tais questões, mesmo assim questionamos: Qual tem sido realmente o empenho da escola em desenvolver habilidades de leitura nos alunos? Se há essa inquietação com as respectivas 


\section{Revista de Estudos Acadêmicos de Letras}

atividades, como a escola tem desenvolvido nos alunos a capacidade de fazerem uso da leitura de forma competente na vida em sociedade? Se a escola tem feito a leitura e a escrita como fatores basilares, por que isso não é reproduzido numericamente nos dados dos exames nacionais? Quais as habilidades em leitura são desenvolvidas nos alunos?

A escolha desta temática para análise advém de algumas inquietações que acometem não apenas aos pesquisadores mais atentos, mas também a maioria dos profissionais da Educação, e em especial os professores que tratam do ensino da língua materna e/ou estrangeira. Foi possível observar que já existe uma série de pesquisas que se debruça sobre a temática da leitura, mas não são tantas, especificamente questão da concepção de leitura vinculada ao exame do ENEM, na rede Estadual de Ensino em Alagoas, o que de certa forma não tem conseguido apresentar respostas para as inúmeras investigações propostas por pesquisadores inquietos e que buscam no estudo científico dar respostas concretas para a academia, para instituição escolar, para os discentes da rede pública de Alagoas, ainda assim, para a sociedade. É preciso, primeiramente, verificar quais as concepções de leitura existentes e a qual tomaremos como base de fundamentação para esse trabalho.

\section{CONCEPÇÃO DE LEITURA}

Considerando que a leitura é uma atividade multifacetária, o que define a posição de Koch (2014, p. 201), quando argumenta que, para pensar nas múltiplas concepções de leitura é preciso levar em considerações outros conceitos, aos quais a leitura tem íntima relação, que são os "conceito de sujeito, de língua, de texto e de sentido que se adote".

Em uma outra perspectiva, Jouve (2002, p. 17) ${ }^{3}$ baseado nos estudos de Gilles Thérien (1990, p. 1-4 $)^{4}$, defende que o processo do ato de ler e a concepção de leitura se dá em cinco dimensões, a saber: processo neurofisiológico, processo cognitivo, processo afetivo, processo argumentativo, processo simbólico.

Para Eni Orlandi (1988, p. 08), em uma perspectiva discursiva (do ponto de vista da Análise do Discurso Francesa), ao tratar da polissemia da noção de leitura, a respectiva estudiosa inicia seu livro "Discurso e Leitura" dizendo que "seria interessante...distinguir os vários sentidos que se toma a leitura" e que, a noção de leitura pode ser vista numa "concepção mais ampla", na concepção de "leitura de mundo", na noção de leitura no "sentido mais 


\section{Revista de Estudos Acadêmicos de Letras}

restrito", vinculada a ideia de "a construção de um aparato teórico e metodológico de aproximação de um texto". Ainda assim, em um "sentido ainda mais restrito", acoplada ao termo "escolaridade", à ideia de (aprender a ler e escrever).

Para Geraldi (2012, p .91-99) é possível pensar na noção de prática de leitura em pelo menos quatro perspectivas: "A leitura - busca de informações"; "A leitura - estudo do texto"; "A leitura - pretexto" e "A leitura - fruição do texto".

Para Bourdieu e Chartier (2011) $)^{5}$, "as leituras são sempre plurais, são elas que constroem de maneira diferente o sentido dos textos, mesmo se esses textos inscrevem no interior de si mesmos o sentido de que desejariam ver-se atribuídos". Tal concepção coaduna com o que defende Jouve (2002, p.17), para quem a leitura é "uma atividade com várias facetas".

Franco $\left(2011\right.$, p. 27) ${ }^{6}$ discorre que a noção de leitura atualmente é estudada sobre três abordagens, quais sejam, “decodificadora, psicolinguística e interacional”. Segundo esse autor, apoiado nas discussões feitas por Silva (2004) ${ }^{7}$, “esses modelos de leitura implicam diferentes conceitos de linguagem". Tais concepções são compreendidas da seguinte forma: "Na concepção decodificadora, a linguagem é espelho do raciocínio; para a abordagem psicolinguística, a linguagem é instrumento de comunicação; e, no último modelo de leitura, a linguagem é vista como processo de interação.

Silveira e Oliveira $(2015)^{8}$ consideram que a compreensão do termo leitura e seu respectivo estudo estão relacionados a diversos aspectos e abordagens, tais como "aspectos econômico, cultural e ideológicos", dentre outros. Para os autores, esses aspectos e abordagens são "interdependentes" com "inter-relacionamento, às vezes, decisivos". Em que, conforme idem, o "fato de não gostar de ler" pode ter uma possível relação com a falta de fluência na leitura, ou ainda, segundo eles, "ao fato de se ter dificuldade de ler" pode estar plenamente ligada à inabilidade de decodificação do texto escrito. Nesse aspecto, em conformidade com os autores, quando o leitor não consegue dominar os "procedimentos cognitivos e estratégicos" da leitura, a atividade de ler tende a se transformar em algo árduo.

Os referidos autores enfatizam que "cada um desses aspectos podem ser considerados como verdadeiras abordagens para o estudo e a pesquisa sobre leitura”. Quando vão tratar de

5 CHARTIER, R, et ali. Práticas da Leitura, , 5a . ed.- São Paulo: Estação Liberdade. 2011

6 TAVARES, K. C. A.; BECHER-COSTA, S. B. A.; FRANCO; C.P. Ensino de Leitura: fundamentos, práticas e reflexões para professores da era digital, Rio de Janeiro: Faculdade de Letras da UFRJ, 2011.

7 SILVA, S. R. Concepção sócio-interacional de leitura: abordagens teóricas e práticas a partir de dois textos escritos. Revista Linguagem em (Dis)curso, vol.4, n.2, 2004. Disponível em: <http://www3.unisul.br/paginas/ensino/pos/linguagem/0402/04.htm> Acessado em 25 de out. 2010.

8 SILVEIRA, M.I.M; OLIVEIRA, J.D. Leitura: Abordagem Cognitiva - Maceió - AL, EDUFAL, 2015. 


\section{Revista de Estudos Acadêmicos de Letras}

201

tais aspecto, Silveira e Oliveira (2015) acrescentam outros, os quais não haviam mencionado anteriormente, apresentado de forma mais ampla oito aspectos, os quais, idem defendem serem relevantes para o estudo da leitura. Dentre eles, além do "aspecto afetivo", o qual (GERALDI, 2012) chama de "fruição do texto", Silveira e Oliveira (2015, p. 11-18) elencam os "aspectos políticos e sociais", “aspectos culturais", "aspectos ideológicos", “aspectos históricos e etnográficos", "aspectos semióticos", "aspectos pedagógicos e instrucionais", por fim e não menos importante, elencam os "aspectos cognitivos e sociocognitivos".

Apesar de a leitura ser uma atividade multifacetária, convém salientar, como enfatiza Marcuschi (2008) $)^{9}$, que a "leitura ... não é uma atividade de vale tudo", para esse autor, "um texto permite muitas leituras, mas não infinitas". O que não dizer, necessariamente, quantas leituras e compreensões podemos atribuir a um texto, entretanto, é possível prever que algumas leituras, a depender do contexto e do texto, não se sustentam de forma significativa, uma vez que é impossível atribuir sentido a determinadas leituras, uma vez que o texto não lhe autoriza determinada leitura. A exemplo, do que não se pode entender de forma contrária a leitura daquilo que o texto propõe. O que corrobora com a ideia de compreensão de texto proposta por esse autor, de que "compreender é produzir modelos cognitivos compatíveis preservando o valor-verdade" (MARCUSCHI, 2008, p. 257). Nesse aspecto, cabe acrescentar o que defende Descartes (1997), para quem, o "conhecimento (compreensão) ${ }^{10}$ não repousa nas ilusões dos sentidos, mas no entendimento. Para ele, pensar é ser (cogito ergo sum) e é pelo pensamento que sou. O entendimento não é uma parte, uma faculdade da alma, mas, sim, ela por inteiro”.

Para Marcuschi (1996, p. 75) ${ }^{11}$, podemos ler um texto de várias maneiras. "Essas diferentes maneiras são horizontes ou perspectivas diversas". Conforme esse teórico, primeiramente, há uma ideia de falta de horizonte, o que para ele, a leitura e compreensão do texto que se apoia nessa perspectiva seria a de que caberia ao leitor apenas repetir o que estava sendo enunciado no texto. Nesse aspecto, seria como pudesse inferir que um determinado texto contém apenas "informações objetivas inscritas de modo transparente". Nisso, o ato de ler não passaria de uma atividade que se reduz ao exercício de repetição. Embora possamos deduzir que, "repetir um texto nem sempre é garantia de que se compreendeu efetivamente".

Em uma noção de horizonte mínimo, Marcuschi (1996, p. 75) entende que nesse processo têm-se, "o que aqui se chama de leitura parafrástica", de outra forma, seria uma

9 MARCUSCHI, L.A. Produção textual, análise de gêneros e compreensão. São Paulo: Parábola, 2008.

10 Grifo nosso.

11 MARCUSCHI, L. A. (1996). Exercícios de compreensão ou copiação nos manuais de ensino de língua? Em aberto, 16(69), 63-82 
repetição por meio de outras palavras, ou paráfrases. Embora tal processo corrobore para a retomada anafórica, é possível a introdução de novas informações ou um dado novo, mesmo assim, pode-se compreender que a interferência do leitor é tão simplória ao ponto de "a leitura ficar ainda numa atividade de identificação de informações objetivas que podem ser ditas com outras palavras".

Idem defende a existência de horizonte máximo, que é o processo pelo qual a compreensão transpõe as barreiras da falta de horizonte, que é a repetição do dito, e o horizonte mínimo, que é reformulação textual, por intermédio de paráfrases. Consideradas como primordiais, as atividades de inferências textuais seriam, portanto, apropriações de conhecimentos presentes no mesmo texto, e/ou introdução de informações e conhecimentos pessoais adquiridos nos contextos sociais e outros textos.

Quando o leitor transpõe a compreensão daquilo ao qual o texto se propôs, esse sujeito penetra no limite da interpretabilidade, isto é, extrapola as ideias do texto, se situando no campo “das leituras pessoais" ou das interpretações pessoais, não autorizadas pelo texto. Tal processo é nomeado por Marcuschi (1996, p. 76) como "horizonte problemático", ou "vale-tudo".

Por último, e não menos importante, o respectivo mestre nos ensina que no horizonte indevido, o leitor faz uma leitura totalmente errada ou indevida de um texto.

Por exemplo, após a leitura do poema "O bicho" de Manoel Bandeira:

\author{
O Bicho \\ Vi ontem um bicho \\ Na imundície do pátio \\ Catando comida entre os detritos. \\ Quando achava alguma coisa, \\ Não examinava nem cheirava: \\ Engolia com voracidade. \\ O bicho não era um cão, \\ Não era um gato, \\ Não era um rato. \\ O bicho, meu Deus, era um homem.
}

Se o leitor compreendesse que se tratava de "um animal feroz, que era mistura de um gato e um rato, comendo um homem", teríamos, em consonância com o autor, uma leitura indevida ou inadequada, tendo em vista que não há sequer nas entrelinhas ideias que corroborem a essa interpretação. 


\section{Revista de Estudos Acadêmicos de Letras}

Para finalizar, no livro "Aula de Português: Encontro \& Interação", Irandé Antunes (2003, p. 2003) ${ }^{12}$ aponta algumas implicações para algumas abordagens no uso da leitura, dentre elas, a de que a leitura deve ser de textos autênticos, uma vez que, segundo essa autora, não há como "justificar uma leitura de um texto seja de um texto autêntico...Texto que tenha "autores, que "têm data de publicação", "que apareçam em algum suporte da comunicação social".

Além do exposto, a autora defende que é preciso que haja "uma leitura interativa", para quem, o "texto lido precisa ser lido como sendo o lugar de um encontro" entre o escritor e o leitor. Essa abordagem não apenas coaduna, mas também complementa uma outra defendida pela autora em tela, que é a "leitura em duas vias", idem, diz que "nenhuma leitura está desvinculada das condições em que o texto foi escrito" (ANTUNES, 2003, p. 80). Por sua vez, há uma interação entre escrita e a leitura. Dessa relação, podemos inferir, primeiramente, que qualquer que seja a atividade de texto escrito se supõe uma atividade de leitura, ainda assim, podemos inferir igualmente que, para que a leitura tenha sentido, cabe uma interação entre texto, leitor, produtor do texto e as condições de produção.

Dentre outras abordagens, Antunes (2003, p. 80-85) defende a abordagem denominada de "leitura motivada", "leitura do todo", "leitura crítica", "leitura da reconstrução do texto", "leitura diversificada", "leitura por pura curtição", "leitura apoiada no texto", "leitura não só das palavras", por fim e não menos importante "leitura nunca desvinculada do sentido".

Embora compreendamos que caberia uma discussão sobre as noções aqui apresentadas, para isso, verificar a bibliografia resenhada, por questões didáticas e não é querer, necessariamente, confrontar hipóteses $\mathrm{A}$ ou $\mathrm{B}$, muito menos validar ou preterir determinado teórico, mas reconhecê-los como complementares, optamos por não discuti-las, mas reconhecer a ideia de multifacetação e multi-teorização da leitura.

\section{TEXTOS ESCRITOS E A LEITURA DE TEXTOS}

Tem sido apontado como lugar comum na literatura linguística, que trata da temática leitura, que o processo de ler é uma atividade extremamente complexa, uma vez que não envolve apenas questões de ordem meramente semânticas, como é o caso da decodificação de uma palavra, mas, a todo o processo, estão envolvidas questões do campo cultural, ideológico, filosófico, fonético, dentre outros, capazes de produzir relações de sentidos diversas a um determinado texto.

12 ANTUNES, M. I. Aula de português - encontro \& interação. - São Paulo: Parábola Editorial, 2003. 


\section{Revista de Estudos Acadêmicos de Letras}

Para Cagliari (2009, p. 12), o ato de ler se constitui uma "atividade profundamente individual", esse autor acrescenta que "duas pessoas dificilmente fazem uma mesma leitura de um texto". Essa postulação parte do princípio de que cada leitor traz suas próprias experiências de leitura, experiências linguísticas que são únicas, além disso, carrega uma série de elementos culturais, ideológicos, filosóficos e ainda fonéticos, os quais levam a uma compreensão ímpar diante de um texto.

Além dos aspectos citados, vale destacar a "experiência de vida", uma vez que, conforme o teórico aludido, a "experiência da vida não se reduz à leitura", visto que, há quem nunca frequentou um banco escolar, mas obteve sucesso na vida financeira. Isso não necessita dizer que a leitura seja um elemento a ser desconsiderado, ou que tal sucesso é uma regra, e ainda, que as pessoas que galgaram tais posições são pessoas dotadas de grandes bens culturais, ao contrário disso, segundo o autor, "por mais rica ( a experiência de vida ${ }^{13}$ ) que possa ser, não é suficiente para fornecer uma cultura sólida e geral". Nisso repousa o papel da escola na oferta de possibilidades de leitura aos discentes de forma geral.

Aqui, porém, serão tratadas ofertas de possibilidades de leitura do ponto de vista das questões inerentes à leitura linguística, embora, a literatura sobre o tema nos aponte uma diversidade de leituras a ser reconhecida como objeto de pesquisa, esse trabalho recebe um recorte didático e metodológico de uma percepção de leitura do ponto de vista linguístico, visto que, abordar outro viés demandaria implicações diferentes por se tratar de hipóteses diferentes, além disso, didaticamente não seria possível nesse trabalho acercar-se das diversas perspectivas do ato de ler, tanto por serem questões diferentes, como não ser essa direção que traçamos, e ainda, não haver espaço físico nesse trabalho para nos debruçarmos a tal pesquisa.

Nesse aspecto, reconhecemos prontamente que ler diz respeito a um ato de decifração e decodificação. Quando se trata da leitura da palavra escrita, a primeira habilidade que o leitor precisa ter desenvolvida é a capacidade de decifrar a escrita, visto que, não poderá alcançar uma ulterior habilidade requerida para ao ato de ler, que é a decodificação, sem que primeiro não decifre o que está escrito. Sem a primeira habilidade seria como um leitor proficiente em língua portuguesa tentasse ler um texto em mandarim sem que tivesse conhecimento dos símbolos gráficos desse idioma. Poderia inclusive após a tradução compreender o que estava escrito, mas na língua de origem não o faria pela ausência de capacidade de decifrar o que estava escrito. 


\section{Revista de Estudos Acadêmicos de Letras}

Cagliari (2009, p.133) enfatiza que "a leitura sem decifração não funciona corretamente", de igual modo, esse autor enfatiza que "sem a decodificação e demais componentes referentes à interpretação, $\left(\right.$ a leitura $\left.^{14}\right)$ se torna estéril e sem grande interesse". Logo, nos damos conta de que a concepção de signo linguístico defendida por Saussure $(2006)^{15}$, para quem, o signo linguístico se estabelece pela união de um significante e um significado, é contemplada nesse aspecto, pela leitura do ponto de vista linguístico. Se consideramos, portanto, o pensamento de Cagliari (2009, p.133), para quem, numa concepção de "leitura como atividade estritamente linguística se monta da fusão do significado e significante", estamos dialogando com o princípio básico do signo linguístico saussuriano.

Esse autor diz que "É falso dizer que pode ler só pelo significado ou pelo significante", uma vez que para tal teórico "um sem o outro jamais constituem uma realidade linguística". Longe de pensar que a leitura é meramente a soma da decifração e decodificação, mais do que isso, o processo de leitura compreende sim os elementos citados, mas não apenas eles, assim como a interação do leitor com o texto ou/e os textos e escritor. na verdade, compreende "uma prática social que remete a outros textos e outras leituras" (KLEIMAN, 2002, p.10) ${ }^{16}$.

Há de se considerar que outros elementos, que não os linguísticos, influenciam no processo da leitura, visto que os rudimentos meramente da língua não dão conta do processo de compreensão textual em um todo, sem que não se faça uso de outros fatores, como culturais, ideológicos, filosóficos etc. Seria, pois, um erro pensar que aprendizes de realidades sociais diferentes, mesmo que consigam decifrar e decodificar um mesmo texto, fariam leituras semelhantes, uma vez que, cada um sofre influências diferentes, isso devido aos meios sociais a que estão expostos. Ainda assim, se fosse de mesmas realidades sociais, suas leituras seriam no mínimo díspares, devido suas visões de mundo diferentes.

No que diz respeito ao ato de ler, há outras questões a serem consideradas. A exemplo de "ser a leitura na sua essência uma atividade individual" (CAGLIARI, 2009, p .134), estabelece, nesse aspecto, que não cabe a escola ou mesmo ao professor adotar a leitura apenas como elemento de análise para outros fins, como a percepção de determinada pronúncia, processo de presteza com que o aprendiz decifra determinadas palavras e textos, aplicar a leitura apenas ao estudo do texto.

14 Grifo nosso.

15 SAUSSURE, F. Curso de linguística geral. São Paulo: Cultrix, 2006.

16 KLEIMAN. A. Oficina de Leitura: Teoria e Prática. Campinas. São Paulo: Pontes, 2002. 


\section{Revista de Estudos Acadêmicos de Letras}

206

Nesse sentido, considere-se que os gêneros textuais emergem com a necessidade de atender uma demanda social a que estão vinculados, cada um emana de uma dada esfera da sociedade, seja ela acadêmica, jornalística, jurídica, religiosa etc. Tal vínculo tem o objetivo de atender às necessidades e atividades socioculturais particulares, com propósitos díspares, a exemplo de: informar, opinar, divertir, instruir etc. - logo, o processo de leitura de imediato também segue tais escopos.

Tal ideia corrobora com o pensamento de Kleiman $\left(1999\right.$, p. 65) ${ }^{17}$, para quem "o papel do leitor não consiste em apenas $\left(\right.$ obter $\left.^{18}\right) \ldots$ informações", a concepção de que o sentido do texto está pronto e acabado, ou a de que o leitor seria um sujeito passivo. Ao contrário, convém perceber o ato de ler como a compreensão do mundo que nos cerca, é um processo fundamentalmente interativo, no qual, ao leitor convém considerar, além dos objetivos do autor, os seus próprios, para que possa, então, construir o seu sentido para o texto. Assim, ler é mais do que obter as informações postas, mas trazer novas informações para o que está posto. Seria um processo interativo entre o leitor-texto-autor.

Essa noção de leitura é constituída pela ideia de o ato de ler ser um processo social e cognitivo, visto que o leitor constrói o sentido por meio de sua relação com fatores sociais que influenciam sua leitura e compreensão, assim como, checar as informações presentes no texto, confirmando ou negando determinadas significações previstas para um dado texto, julgando ser pertinentes ou não, tomando como base os conhecimentos prévios, fatores sociais, cotexto, contexto, condição de produção, visão de mundo e conhecimento linguístico. Nesse aspecto, o sentido não está necessariamente, nem no texto, muito menos na mente do leitor, mas no processo interativo desses dois domínios.

Com relação à noção de que o sentido do texto está, necessariamente, ligado à extração do significado no interior do texto, Leffa (1996, p. 12) ${ }^{19}$ esboça que "Essa leitura extração-designificado está associada à ideia de que o texto tem um significado preciso, exato e completo, que o leitor-minerador pode obter através do esforço e da persistência". Nesse aspecto, é possível inferir que o sujeito leitor está de alguma forma submisso à materialidade textual, tal elemento passa a ser o mais importante no ato de ler. Logo, se o ledor entra em contato com um texto rico, esse será de alguma maneira enriquecido pela materialidade discursiva que o texto apresenta. Ao contrário disso, se o material textual a que o sujeito for exposto for pobre,

17 KLEIMAN, A. B. \& MORAES, S. E. Leitura e interdisciplinaridade: tecendo redes nos projetos da escola. Campinas-SP: Mercado de Letras, 1999.

19 LEFFA, V. J.. Aspectos da leitura. Porto Alegre: Sagra: DC Luzzatto, 1996. 


\section{Revista de Estudos Acadêmicos de Letras}

tem-se que esse sujeito perderá o tempo investido em sua compreensão, pelo fato de ele pouco apresentar a ser extraído após a sua compreensão.

Isso gera uma outra questão que precisa ser considerada, a de que o processo da leitura não está exatamente em compreender ou não o texto, mas os meios que o leitor usou para construção desse sentido. E de que a leitura é um processo que evolui do menor para o maior, de letras a sílabas, de sílabas a palavras, de palavras a palavras, de palavras a frases, de frases a parágrafos, de parágrafos a textos. 


\section{CONCEPÇÃO DE LEITURA SUBJACENTE AO REFERENCIAL CURRICULAR DE ALAGOAS E CADERNOS DO AREAL ${ }^{20}$.}

A Rede estadual de ensino em Alagoas em seus documentos oficiais, assim como, por meio de outros meios não oficializados, compreende a concepção de leitura em uma perspectiva sociointeracionista, uma vez que em seus documentos há a defesa de que a leitura é um instrumento capaz de tornar efetiva as práticas sociais em que o educando se ver inserido. Tais documentos propõem que a escola deva propiciar a possibilidade de leitura que favoreça ao uso dessas práticas em contextos extraescolares. Para isso, é perceptivelmente reconhecido que a educação escolar proporcionada pela Rede Oficial de Ensino de Alagoas deverá, sobretudo, estar vinculada a uma prática interdisciplinar das áreas que compõem a base curricular de ensino e a linguagem, uma vez que tal prática será capaz de desenvolver no discente a capacidade de proficiência que o ENEM exige. Em (ALAGOAS, 2014, p.73) ${ }^{21}$ indica-se que:

A atual organização da Educação Básica propõe uma perspectiva interdisciplinar dos estudos, interligando as áreas de conhecimento e as linguagens e suas tecnologias com o objetivo de formar cidadãos proficientes na leitura e produção textual de textos impressos e digitais, que possam participar efetivamente de práticas sociais que acontecem dentro e fora da escola.

Segundo o Referencial, “A língua, como uma das manifestações da linguagem, é o patrimônio cultural simbólico de um povo e está presente em todas as manifestações artísticas e culturais e no cotidiano de cada cidadão" (ALAGOAS, 2014, p. 81). Nesse aspecto, tem-se que a língua propicia aos educandos sujeitos capacidade de construir sentidos para práticas sociais, isso por que fazer uso de uma língua não é apenas a aprendizagem de palavras, sons e construções de regras estruturais ou combinações de palavras, sons e estruturas, mas apre(e)nder sentidos culturais e fazer interpretações da realidade em um processo interacional. Nesse aspecto, (ALAGOAS, 2014, p. 81) defende que:

\footnotetext{
a leitura e o estudo da literatura também são fundamentais e enriquecedores para a formação dos estudantes, pois possibilitam conhecer os usos estéticos da linguagem e, desse modo, ter contato significativo com o belo, com outros mundos possíveis, com a experiência sensível, tão desvalorizada nos tempos atuais.
}

20 Sistema de Avaliação de Aprendizagem da Rede Estadual de Ensino de Alagoas (AREAL) implantado em 2012, o AREAL objetiva fornecer um diagnóstico do desempenho dos alunos e, por conseguinte, da rede estadual de ensino de Alagoas, em relação aos conteúdos essenciais da educação básica, nas disciplinas de língua portuguesa (leitura e produção de texto) e matemática. Em sua primeira edição, foram avaliados 29.471 alunos matriculados nos anos/séries finais de cada etapa de ensino, a saber: $5^{\circ}$ e $9^{\circ}$ anos do ensino fundamental e $3^{\mathrm{a}}$ série do ensino médio.

21 ALAGOAS. Secretaria de Estado da Educação e do Esporte - SEE - Referencial Curricular da Educação Básica da Rede Estadual de Ensino de Alagoas. Educação Básica. Referencial Curricular. Linguagens. Maceió.AL, 2014. 


\section{Revista de Estudos Acadêmicos de Letras}

Essa visão corrobora com a ideia de que o trabalho desenvolvido pelas instituições educacionais, que se pautam na perspectiva da interação, é de uma visão predominantemente discursiva, considerando que a produção dos sentidos se efetiva principalmente nas relações interlocutivas entre falante/escritor, ouvinte/leitor e sobre o que se fala/escreve em determinado contexto de interações sociais. Nessa perspectiva, é possível inferir que no processo de interação os interlocutores envolvidos não são mais pessoas do discurso vistas de forma isolada, cuja tônica se dar, necessariamente, numa perspectiva comunicativa; mas são vozes sociais ou discursivas constituídas sócio historicamente.

Para (ALAGOAS, 2014, p. 81), “o texto é fruto da interação dialógica das pessoas, ele também dialoga com outros textos, ou seja, há sempre a presença do outro naquilo que dizemos”. Essa concepção de texto que o Referencial Curricular da Educação Básica da Rede Estadual de Ensino do Estado de Alagoas de Linguagem (doravante também será grafado como RECREAL) defende são proposições que têm sido defendidas pela maioria dos teóricos do texto atualmente, dentre eles, é possível apontar para Antunes (2010, p. 37) ${ }^{22}$ que discute a respectiva ideia, mencionando que: "Quem recorre à palavra do outro, faz ou para apoiar-se nessa palavra, ou para confirmá-la ou para refutá-la. Ou seja, o recurso à palavra do outro responde a alguma estratégia argumentativa”. Nesse aspecto, todo texto é uma resposta a um outro texto antes falado ou escrito, uma vez que aquilo que falamos não passa de memória discursiva presente na coletividade que tomamos para nós como se fossem nossos esses dizeres.

Convém ressaltar que o RECREAL propõe que, para o ensino da língua portuguesa, sejam considerados os seguintes aspectos: competências, eixos, habilidades e conteúdos conceituais. O respectivo Referencial explica tais termos, dizendo que:

(a) competências, ou seja, capacidades amplas construídas a partir de conhecimentos, atitudes e aptidões que habilitam alguém para vários desempenhos da vida;

(b) eixos: oralidade/escuta, leitura, escrita e análise linguística; e conteúdos;

(c) habilidades, ou seja, capacidades específicas dos estudantes, possíveis de serem ensinadas (equivalentes a conteúdos procedimentais) e;

(d) conteúdos conceituais, ou seja, temas, conceitos, princípios teóricos, fatos etc. (ALAGOAS, 2014, p. 84).

22 ANTUNES, Irandé. Análise de textos: fundamentos e práticas. São Paulo: Parábola Editorial, 2010. 


\section{Revista de Estudos Acadêmicos de Letras}

O RECREAL (ALAGOAS, 2014, p. 84) divide o tema leitura em três Eixos, sendo: Leitura, Leitura do Texto Literário e Leitura Procedimentos de Estudo, nos três anos do Ensino Médio. Vejamos:

\begin{tabular}{|c|c|c|c|}
\hline \multicolumn{4}{|c|}{ COMPONENTE CURRICULAR:LINNGUA PORTUGUESA — I' SEERIE - MÉDIO } \\
\hline COMPETÊNCIA & EIXOS & HABILIDADE & CONTEÚDOS CONCEITUAIS \\
\hline $\begin{array}{l}\text { Utilizar a lingua portuguesa nos trés niveis de } \\
\text { competência: interativa, textual e gramatical; } \\
\text { Analisar, interpretar e aplicar os recursos } \\
\text { expressivos das linguagens, relacionando textos } \\
\text { com seus contextos; } \\
\text { Compreender os valores sociais implicados na } \\
\text { variaçäo linguistica que hierarquizam os usos; } \\
\text { Utilizar as diferentes linguagens nos eixos da } \\
\text { representaçáo simbólica artística nos trếs niveis } \\
\text { de competência } \\
\text { Conceber a linguagem digital como prática social }\end{array}$ & Leitura & 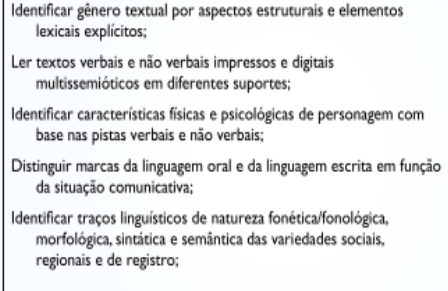 & 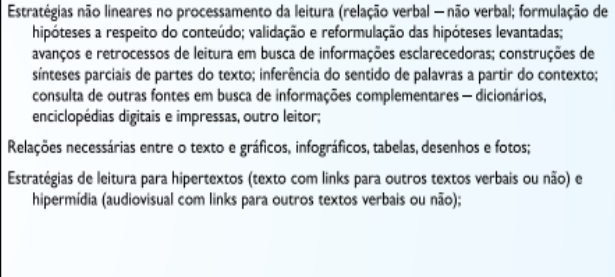 \\
\hline \multirow{2}{*}{$\begin{array}{l}\text { Conceber a linguagem digizial como prizica social } \\
\text { nos trés niveis de competência (interacional, } \\
\text { textual e gramatical). }\end{array}$} & $\begin{array}{l}\text { Leitura do texto } \\
\text { literário }\end{array}$ & 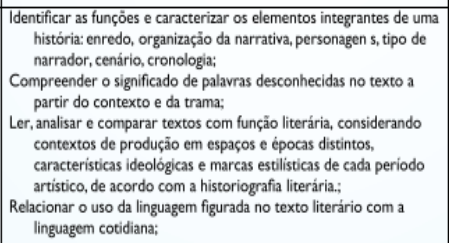 & $\begin{array}{l}\text { Estudo das escolas literárias a partir de textos de referência: } \\
\text { Classicismo (aspectos introdutórios) } \\
\text { - Barroco e Arcadismo } \\
\text {. Relaçōes entre os diferentes periodos } \\
\text { artistico-literários e os textos da contemporaneidade. } \\
\text { Caracteristicas da literatura no meio digital (ciberpoema/infopoesia, minisséries digitais, } \\
\text { narrativas hipermidiáticas); }\end{array}$ \\
\hline & $\begin{array}{l}\text { Leitura/Procedimentos } \\
\text { de Estudo }\end{array}$ & 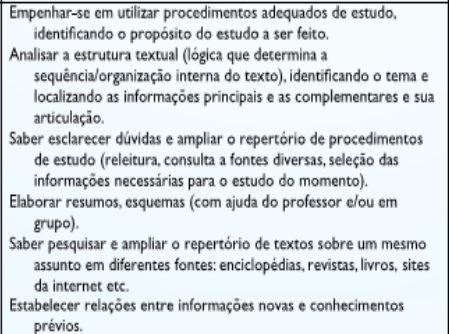 & 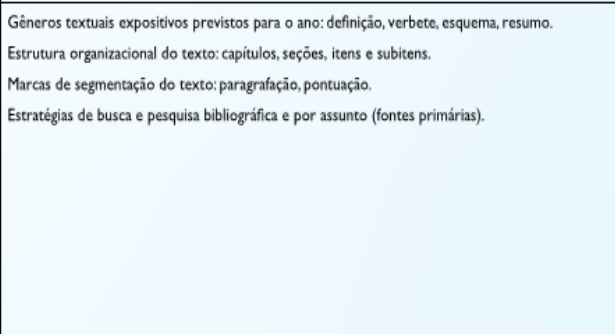 \\
\hline
\end{tabular}

Imagem 01 - Fonte - Referencial Curricular. Linguagens. Maceió AL, 2014

\begin{tabular}{|c|c|c|c|}
\hline \multicolumn{4}{|c|}{ COMPONENTE CURRICULAR:LINGUAA PORTUGUESA $-2^{2}$ SÉRIE - MÉDIO } \\
\hline COMPETENCIA & EIXOS & HABILIDADE & CONTEÚDOS CONCEITUAIS \\
\hline $\begin{array}{l}\text { Utilizar a lingua portuguesa nos três } \\
\text { niveis de competência: } \\
\text { interativa, textual e gramatical; } \\
\text { Analisar, interpretar e aplicar os } \\
\quad \text { recursos expressivos das } \\
\quad \text { linguagens, relacionando textos } \\
\quad \text { com seus contextos; } \\
\text { Compreender os valores sociais } \\
\text { implicados na variação } \\
\text { linguistica que hierarquizam os } \\
\text { usos; } \\
\text { Utilizar as diferentes linguagens nos } \\
\text { eixos da representação } \\
\text { simbólica artistica nos três }\end{array}$ & Leitura & $\begin{array}{l}\text { Confrontar opiniōes e pontos de vista a partir de textos } \\
\quad \text { argumentativos; } \\
\text { Ler textos verbais e não verbais impressos e digitais } \\
\quad \text { multissemióticos (produzidos com diferentes linguagens); } \\
\text { Identificar o tema de um texto, relacionando-o ao gênero e ao } \\
\quad \text { contexto; } \\
\text { Reconhecer clichês e estereótipos no processo de leitura; } \\
\text { Identificar as motivaçōes pelas escolhas e não-escolhas feitas pelo } \\
\quad \text { autor; }\end{array}$ & $\begin{array}{l}\text { Seleção dos procedimentos de leitura em função dos interesses de leitura do } \\
\text { sujeito (estudo, formaçąo pessoal, entretenimento, realização de tarefa); } \\
\text { Estratégias não lineares no processamento da leitura (relação verbal - não- } \\
\text { verbal; formulação de hipóteses a respeito do conteúdo; validação e } \\
\text { reformulação das hipóteses levantadas; avanços e retrocessos de leitura } \\
\text { em busca de informaçōes esclarecedoras; construçōos de sinteses parciais } \\
\text { de partes do texto; inferência do sentido de palavras a partir do contexto; } \\
\text { consulta de outras fontes em busca de informaçōes complementares - } \\
\text { dicionários, enciclopédias digitais e impressas, outro leitor; } \\
\text { Relaçōes necessárias entre o texto e gráficos, infográficos, tabelas, desenhos e } \\
\text { fotos; } \\
\text { Estratégias de leitura para hipertextos (texto com links para outros textos } \\
\text { verbais ou não) e hipermídia (audiovisual com links para outros textos } \\
\text { verbais ou não): }\end{array}$ \\
\hline $\begin{array}{l}\text { niveis de competência } \\
\text { Conceber a linguagem digital como } \\
\text { prática social nos três niveis de } \\
\text { competência (interacional, } \\
\text { textual e gramatical). }\end{array}$ & $\begin{array}{l}\text { Leitura do texto } \\
\text { literário }\end{array}$ & $\begin{array}{l}\text { Ler, analisar e comparar textos com função literária, considerando } \\
\text { contextos de produçąo em espaços e épocas distintos, } \\
\text { caracteristicas ideologicas e marcas estilisticas de cada periodo } \\
\text { artistico, de acordo com a historiografia literária; } \\
\text { Relacionar o uso da linguagem figurada no texto literário com a } \\
\text { linguagem cotidiana; }\end{array}$ & $\begin{array}{l}\text { Escolas literárias (estudo a partir de textos de referência): } \\
\text { Romantismo, Realismo/Naturalismo, Simbolismo; } \\
\text { Relaçöes entre os diferentes periodos artistico-literários e os textos da } \\
\quad \text { contemporaneidade; } \\
\text { Características da literatura no meio digital (ciberpoema/infopoesia, } \\
\text { minisséries digitais, narrativas hipermidiáticas); }\end{array}$ \\
\hline & $\begin{array}{l}\text { Leitura/Procedimentos } \\
\text { de Estudo' }\end{array}$ & $\begin{array}{l}\text { Empenhar-se em utilizar procedimentos adequados de estudo, } \\
\text { identificando o propósito do estudo a ser feito. } \\
\text { Analisar a estrutura textual (lógica que determina a } \\
\text { sequência/organização interna do texto), identificando o tema e } \\
\text { localizando as informaçoes principais e as complementares e sua } \\
\text { articulaçāo. } \\
\text { Sabber esclarecer dúvidas e ampliar o repertório de procedimentos } \\
\text { de estudo (releitura, consulta a fontes diversas, seleçāo das } \\
\text { informaçōes necessárias para o estudo do momento). } \\
\text { Elaborar resumos, esquemas (com ajuda do professor e/ou em } \\
\text { grupo). } \\
\text { Saber pesquisar e ampliar o repertório de textos sobre um mesmo } \\
\text { assunto em diferentes fontes: enciclopédias, revistas, livros, sites } \\
\text { da Internet etc. } \\
\text { Estabelecer relaçōes entre informaçōes novas e conhecimentos } \\
\text { prévios. }\end{array}$ & $\begin{array}{l}\text { Gêneros textuais expositivos previstos para o ano: definição, verbete, } \\
\text { esquema, resumo. } \\
\text { Estrutura organizacional do texto: capitulos, seçōes, itens e sub itens. } \\
\text { Marcas de segmentação do texto: paragrafação, pontuação. } \\
\text { Estratégias de busca e pesquisa bibliográfica e por assunto (fontes primárias). }\end{array}$ \\
\hline
\end{tabular}

Imagem 02 - Fonte - Referencial Curricular. Linguagens. Maceió - AL, 2014. 


\section{Revista de Estudos Acadêmicos de Letras}

\begin{tabular}{|c|c|c|c|}
\hline \multicolumn{4}{|c|}{ COMPONENTE CURRICULAR: LINGUA PORTUGUESA - 3’ SÉRIE - MÉDIO } \\
\hline COMPETËNCIA & EIXOS & HABILIDADE & CONTEÚDOS CONCEITUAIS \\
\hline $\begin{array}{l}\text { Utilizar a lingua portuguesa nos três } \\
\text { niveis de competência: } \\
\text { interativa, textual e gramatical; } \\
\text { Analisar, interpretar e aplicar os } \\
\text { recursos expressivos das } \\
\text { linguag̨ens, relacionando textos } \\
\text { com seus contextos; } \\
\text { Compreender os valores sociais } \\
\text { implicados na variação } \\
\text { linguistica que hierarquizam os } \\
\text { usos; }\end{array}$ & Leitura & $\begin{array}{l}\text { Confrontar opiniöes e pontos de vista a partir de textos } \\
\text { argumentativos; } \\
\text { Ler textos verbais e não verbais impressos e digitais } \\
\text { multissemióticos em diferentes suportes; } \\
\text { Entender a realidade como construção sociossimbólica; } \\
\text { Reconhecer clichés e cstercótipos no processo de leitura; } \\
\text { Identificar as motivaçöes pelas escolhas e näo-escolhas feitas pelo } \\
\text { autor; }\end{array}$ & 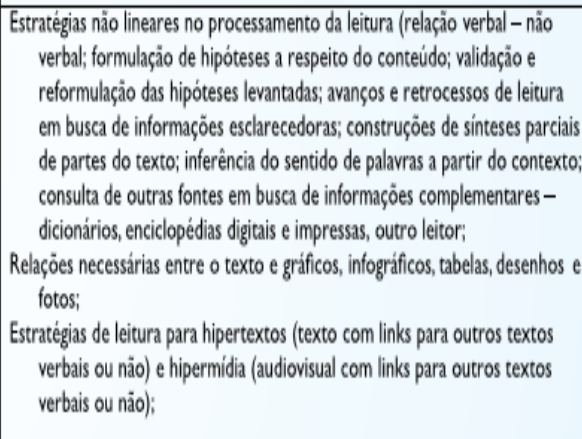 \\
\hline \multirow[t]{2}{*}{$\begin{array}{l}\text { Utilizar as diferentes linguagens nos } \\
\text { eixos da representação } \\
\text { simbólica artística nos três } \\
\text { niveis de competência } \\
\text { Conceber a linguageem digital como } \\
\text { prática social nos très niveis de } \\
\text { competência (interacional, textual e } \\
\text { gramatical). }\end{array}$} & $\begin{array}{l}\text { Leitura do texto } \\
\text { literário }\end{array}$ & $\begin{array}{l}\text { Ler, analisar o comparar textos com função literária, considerando } \\
\text { contextos de produção em espaços e épocas distintos, } \\
\text { caracteristicas ideológicas e marcas estilisticas de cada periodo } \\
\text { artistico, de acordo com a historiografia literária; } \\
\text { Relacionar o uso da linguagem figurada no texto literário com a } \\
\text { linguagem cotidiana: }\end{array}$ & $\begin{array}{l}\text { Escolas literárias (estudo a partir de textos de referéneia): Modernismo / } \\
\text { Literatura contemporânea; } \\
\text { Caracteristicas da literatura no meio digital (ciberpoemalinfopoesia, } \\
\text { minisséries digitais, narrativas hipermidiáticas); }\end{array}$ \\
\hline & $\begin{array}{c}\text { Leitura/Procedimentos } \\
\text { de Estudo }\end{array}$ & $\begin{array}{l}\text { Empenhar-se em utilizar procedimentos adequados de estudo, } \\
\text { identificando o propósito do estudo a ser feito. } \\
\text { Analisar a estrutura textual (lógica que determina a } \\
\text { sequência/organizaçáo interna do texto), identificando o tema e } \\
\text { localizando as informaçôes principais e as complementares e sua } \\
\text { articulação. } \\
\text { Saber esclarecer dúvidas e ampliar o repertório de procedimentos } \\
\text { de estudo (releitura, consulta a fontes diversas, seleção das } \\
\text { informaçōes necessárias para o estudo do momento). } \\
\text { Elaborar resumos, esquemas (com ajuda do professor elou em } \\
\text { grupo). } \\
\text { Saber pesquisar e ampliar o repertório de textos sobre um mesmo } \\
\text { assunto em diferentes fontes: enciclopédias, revistas, livros, sites } \\
\text { da Internet etc. } \\
\text { Estabelecer relaçóes entre informaçōes novas e conhecimentos } \\
\text { prévios. }\end{array}$ & $\begin{array}{l}\text { Gêneros textuais expositivos previstos para o ano: definição, verbete, } \\
\text { esquema, resumo. } \\
\text { Estrutura organizacional do texto: capitulos, seçoes, itens e subitens. } \\
\text { Marcas de segmentaçāo do texto: paragrafação, pontuação. } \\
\text { Estratégias de busca e pesquisa bibliográfica e por assunto (fontes primárias). }\end{array}$ \\
\hline
\end{tabular}

Imagem 03 - Fonte - Referencial Curricular. Linguagens. Maceió - AL, 2014.

Nos documentos relativos ao AREAL, estão propostos padrões de desempenho - $1^{\mathrm{a}}, 2^{\mathrm{a}}$ e $3^{\mathrm{a}}$ séries do Ensino Médio sobre os quais os alunos serão avaliados no que se refere à Língua Portuguesa. A escala de proficiência se dar em horizontalidade e verticalidade. Em relação à horizontalidade, a verificação considera domínios, competências e descritores, já no que se refere à verticalidade, o exame considera Apropriação do Sistema da Escrita, Estratégias de Leitura e Processamento do Texto, embora o mesmo documento enfatiza que não considerará Apropriação do Sistema da Escrita, uma vez que esse critério é destinado apenas para os alunos do Ensino Fundamental.

Em relação ao item Estratégias de Leitura e Processamento do Texto, o sistema de avaliação de Alagoas estabelece competência que o educando precisa apresentar, tais como, Localizar informação, identificar tema, realizar inferência, identificar gênero, função e destinatário de um texto, cada uma dessas competências está associada a um ou mais descritores 


\title{
Revista de Estudos Acadêmicos de Letras
}

da Matriz de Referência de Língua Portuguesa para o Ensino Médio ${ }^{23}$. Igualmente, o item Processamento do Texto dispõe de competências necessárias ao aluno, tais como: Estabelecer relações lógico-discursivas, identificar elementos de um texto narrativo, estabelecer relações entre textos, distinguir posicionamentos, identificar marcas linguísticas, tais competências estão também vinculadas a um ou mais descritores.

A leitura, na rede de ensino em Alagoas, segundo seus documentos oficiais, volta-se, predominantemente, ao uso escolar, embora haja uma relativa divergência entre os RECREAL (2014) e o $\operatorname{AREAL}\left(2015\right.$, p. 09) ${ }^{24}$, em que o último defende que, "O domínio de leitura e escrita, ... possibilita o uso e a compreensão de recursos discursivos os quais auxiliam na interação com o mundo, permitindo efetiva compreensão da realidade e ampla participação social ${ }^{25}$.

Mesmo diante do que foi dito anteriormente, o respectivo documento (AREAL, 2015) coaduna com o que propõe o RECREAL, quando enfatiza que:

\begin{abstract}
Em suma, o que se espera das práticas de ensino de Língua Portuguesa voltadas para a leitura e a escrita, principalmente da produção escrita, é a organização das atividades de forma sequenciada e gradativa, que poderá resolver, progressivamente, as dificuldades dos alunos, facilitando a tomada de consciência das características linguísticas dos textos produzidos e/ou lidos por eles (AREAL, 2015, p. 10).
\end{abstract}

É exatamente o que o RECREAL (2014 p. 164) defende, quando enfatiza que, "Quanto mais a escolaridade avança, maior é a habilidade que se exige dos estudantes para aprender diferentes conteúdos por meio da leitura e para demonstrar por escrito o que aprenderam”.

Essa concepção de leitura proposta pelos documentos oficias da Rede Estadual de Alagoas se contrapõe a ideia de Chartier (2014, p.26) ${ }^{26}$, para quem:

\footnotetext{
Não devemos tampouco isolar os objetos impressos (livros ou revistas) das outras formas de presença da escrita: os cartazes manuscritos, as inscrições gravadas, os escritos pintados encontrados nas ruas, nos cemitérios, nos edifícios públicos, nas casas. Na paisagem escrita urbana, essa onipresença dos textos escritos produz uma aculturação na escrita fora das aprendizagens escolares
}

Embora a maioria dos estudos do texto que se voltam para leitura reconheçam a ideia de que o ato de ler se constitui elemento primordial na associação do que se leu, do que se

23 Estarão em anexo.

24 ALAGOAS. Secretaria de Estado da Educação. Revista Pedagógica - Produção de Texto: AREAL - 2015 MÉDIO/ Universidade Federal de Juiz de Fora, Faculdade de Educação, CAEd. v. 1 ( jan./dez. 2015), Juiz de Fora, 2015 - Anual.

25 Grifo nosso

26 CHARTIER, R. Ler a leitura. In: MORTATTI, M. R.L.; FRADE, I.C.A.S. (org.). História do ensino de leitura e escrita: métodos e material didático. Roger Chartier ... [et al.]. - São Paulo: Editora Unesp; Marília: Oficina Universitária, 2014. P.21-41. 


\section{Revista de Estudos Acadêmicos de Letras}

aprendeu e do que foi lido, há de enfatizar que o processo de leitura não deve ser vinculado estritamente aos elementos textuais e/ou linguístico, mas também aos elementos discursivos e às práticas sociais de forma geral. O que é reforçado, quando o RECREAL (ALAGOAS, 2014, p. 164) enfatiza ainda que "Eles devem escrever o que entenderam do que leram, localizar informações, expressar com suas palavras o que sabem, selecionar aspectos relevantes, fazer resumos, dentre outras habilidades".

\section{CONCLUSÃO}

Embora a proposta defendida pelos documentos considere que a leitura não exija apenas a retenção da informação, mas a transformação dessa informação em conhecimento, acrescenta, ainda, que o ensino da leitura seja uma "tarefa...intransferível da escola", tornando o ato de ler algo estritamente escolar, a ponto de considerar que cabe (à escola, apenas à escola) ensinar aos estudantes "as habilidades que todo leitor competente pode utilizar quando precisa aprender com os textos", desconsiderando, nesse caso, o papel de outras instituições e/ou inserções nas quais o discente se ver inserido. Há de se sopesar que essas instituições ou inserções sociais são capazes de definir os valores que o texto de forma isolada não explicita, o que tornaria definitivamente a "relativa autonomia para selecionar e interpretar de forma adequada aquilo que responde às suas necessidades" e não apenas a leitura como algo fechado no mundo linguístico.

Apesar de compactuarmos com a ideia de o "ensino e os usos da leitura e da escrita" oferecerem ferramentas que contribuem para o êxito escolar do discente", é preciso esclarecer que esse processo só se dar de forma efetiva se o ato de ler estiver vinculado a outras práticas sociais, e não apenas a uma visão voltada para a atividade escolar.

Por fim, e não menos importante, os respectivos Referenciais Curriculares da Rede de Ensino de Alagoas apresentam uma série de atividades que, segundo tais documentos, farão com que o aluno desenvolva competências e habilidades necessárias no que se refere à leitura, dentre eles: relacionar as informações novas com os conhecimentos; resolver dificuldades de compreensão durante a leitura; discutir aspectos relevantes e reorganizar informações para recordar o que foi aprendido. Isso confirma o que tem sido exposto sobre a concepção de leitura adotada pela rede estadual de Educação de Alagoas, que é o processo de leitura linguístico, deixando para um plano secundário a visão social e discursiva do texto.

Embora se considere um contrassenso pensar que, se a escola ensina ler e escrever com o singular desígnio, o de que os discentes tornem-se hábeis em fazê-lo, tais alunos poderão não 


\section{Revista de Estudos Acadêmicos de Letras}

aprender ou desenvolver a função social dessa leitura e escrita, entretanto, caso a escola abdique do propósito didático-pedagógico e encarregue-se apenas da prática social, estará renunciando a sua função de ensinar ou oportunizar que o aluno desenvolva competências na materialidade linguístico-textual. O que fazer então? É preciso desenvolver um trabalho com a leitura que possibilite ao discente a percepção de que ler não é uma atividade restrita ao contexto escolar, mas um elemento presente em sua vida fora da instituição. Nesse aspecto, o ato de ler não é uma tarefa necessariamente escolar, mas para vida, para uma vida inteira, fora ou dentro de instituições escolares, com olhares acadêmicos ou não.

O RECREAL propõe uma série de práticas para a construção de competências e habilidades de decodificação e compreensão textuais, embora tais previsões sejam de situações artificiais de comunicação, as quais, poucos alunos serão inseridos fora da instituição escolar. Nisso, a finalidade de tais práticas fica aquém do plano funcional de tais textos ou leituras, mais ainda, essas atividades pouco se voltarão para a prática de leitura necessária no viver cotidiano e/ou profissional dos alunos.

Nesse aspecto, cabe destacar a necessidade de a Rede Estadual de Ensino de Alagoas desenvolver uma concepção de leitura que extrapole a ideia de ler como aprendizado individual. É preciso, pois, uma compreensão do ato da leitura que perceba a necessidade da apreensão dos sentidos construídos dos textos lidos no ambiente escolar por meio não apenas do acesso à leitura e escrita como práticas individuais, mas também pela conexão da leitura com práticas sociais.

Nesse aspecto, para que a respectiva REDE possa construir praxes de leitura em suas escolas, as quais possibilitem contemplar todas as extensões viáveis do ato de ler como atividade sócio interacional, convém, antes de tudo, desenvolver outra concepção de leitura, uma que acarrete a volta da palavra como indispensável ao pensamento e à subjetividade, e que ainda se fundamente numa concepção de língua capaz de anteferir as interações verbais por meio de práticas didático-pedagógicas atravessadas por sugestões de leitura no âmbito escolar que abarque, sobretudo, todas as cadeias de textos que circulam no corpo social, ampliando, assim, a ideia de leitura de textos para além do objetivo escolar.

\section{REFERÊNCIAS.}

ANTUNES, Irandé. Língua, texto e ensino: outra escola possível. Parábola Editorial, 2009. BAZERMAN, Charles. Escrita, gênero e interação social. São Paulo: Cortez, 2007. 
BATISTA, Ronaldo de Oliveira. O texto e seus conceitos. Parábola Editorial, 2016.

Elias, Vanda Maria. Ensino de língua portuguesa. Editora Contexto, 2011.

GERALDI, João Wanderley. Texto na sala de aula: leitura \& produção. Assoeste, 1985.

KOCH, Ingedore. O texto: construção de sentidos. Organon 9.23 (1997).

e TRAVAGLIA, Luiz Carlos. Texto e coerência. Vol. 4. Cortez Editora, 1989.

. As tramas do texto. Contexto, 2014.

. Desvendando os segredos do texto. Editora Cortez, 2006.

2006. e ELIAS, Vanda Maria. Ler e compreender: os sentidos do texto. Contexto,

PRESTES, Maria Luci De Mesquita. Leitura e (re)escritura de textos: Subsídios teóricos e práticos para o seu ensino. São Paulo - SP, Respel. 2000.

RONCARATI, Cláudia. As cadeias do texto: construindo sentidos. São Paulo: Parábola Editorial, 2010.

SOLÉ, Isabel. Estratégias de leitura. Porto Alegre: Artmed, 1998.

SOUZA, A. C. \& RODRIGUES, C. Protocolos verbais: uma metodologia na investigação de processos de leitura. In: TOMICH, L. M. B. (org). Aspectos cognitivos e instrucionais da leitura. Bauru, SP: EDUSC, 2008.

TEBEROSKY, A. \& COLOMER, T. Aprender a ler e a escrever - uma proposta construtivista. Porto Alegre: Artmed, 2003.

TERZI, S. B. A construção da leitura. Campinas, SP: Pontes, 2002.

TOMICH, L. M. B. (org). Aspectos cognitivos e instrucionais da leitura. Bauru, SP: EDUSC, 2008.

VILLALTA, Luiz Carlos. O que se fala e o que se lê: língua, instrução e leitura. In: SOUZA, L. de M. (org). História da vida privada na América portuguesa, Vol.1. São Paulo: Companhia das Letras, 2004, pp. 332-385 ( $8^{\text {a }}$ reimpressão).

ZILBERMAN, R. \& SILVA, E. T. da (orgs). Leitura: perspectivas interdisciplinares. São Paulo: Ática, 2002. 


\section{MATRIZ DE REFERÊNCIA DE LÍNGUA PORTUGUESA DO ENSINO MÉDIO EM} ALAGOAS

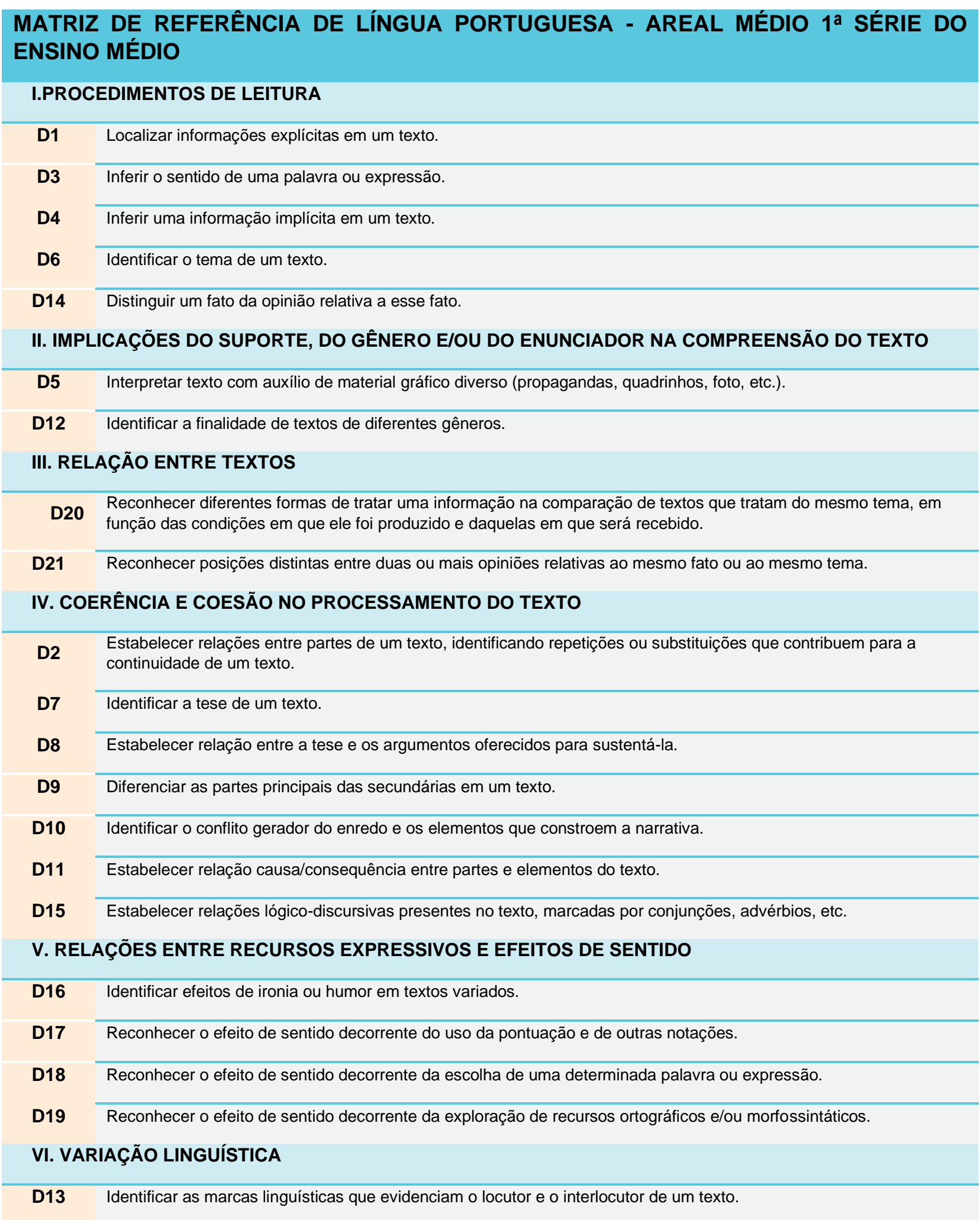




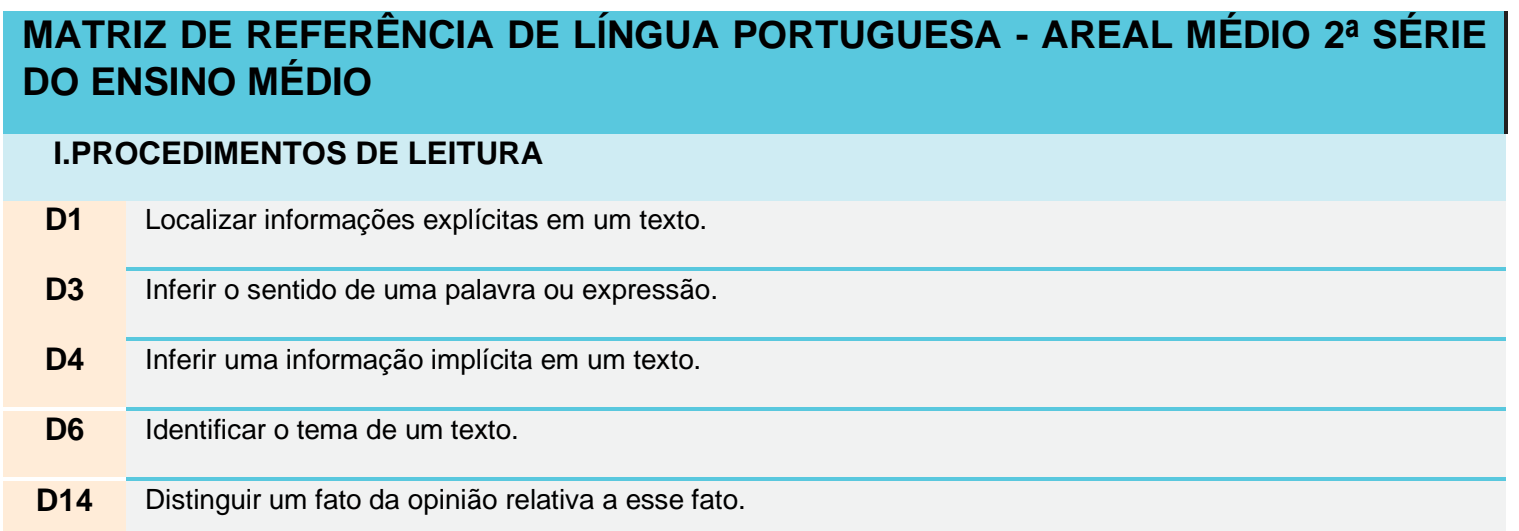

\section{IMPLICAÇÕES DO SUPORTE, DO GÊNERO E/OU DO ENUNCIADOR NA COMPREENSÃO DO TEXTO}

D5 Interpretar texto com auxílio de material gráfico diverso (propagandas, quadrinhos, foto, etc.).

D12 Identificar a finalidade de textos de diferentes gêneros.

\section{RELAÇÃO ENTRE TEXTOS}

D20 Reconhecer diferentes formas de tratar uma informação na comparação de textos que tratam do mesmo tema, em função das condições em que ele foi produzido e daquelas em que será recebido.

D21 Reconhecer posições distintas entre duas ou mais opiniões relativas ao mesmo fato ou ao mesmo tema.

\section{COERÊNCIA E COESÃO NO PROCESSAMENTO DO TEXTO}

D2

Estabelecer relações entre partes de um texto, identificando repetições ou substituições que contribuem para a continuidade de um texto.

D7 Identificar a tese de um texto.

D8 Estabelecer relação entre a tese e os argumentos oferecidos para sustentá-la.

D9 Diferenciar as partes principais das secundárias em um texto.

D10 Identificar o conflito gerador do enredo e os elementos que constroem a narrativa.

D11 Estabelecer relação causa/consequência entre partes e elementos do texto.

D15 Estabelecer relações lógico-discursivas presentes no texto, marcadas por conjunções, advérbios, etc.

\section{RELAÇÕES ENTRE RECURSOS EXPRESSIVOS E EFEITOS DE SENTIDO}

D16 Identificar efeitos de ironia ou humor em textos variados.

D17 Reconhecer o efeito de sentido decorrente do uso da pontuação e de outras notações.

D18 Reconhecer o efeito de sentido decorrente da escolha de uma determinada palavra ou expressão.

D19 Reconhecer o efeito de sentido decorrente da exploração de recursos ortográficos e/ou morfossintáticos.

\section{VARIAÇÃO LINGUÍSTICA}

D13 Identificar as marcas linguísticas que evidenciam o locutor e o interlocutor de um texto. 


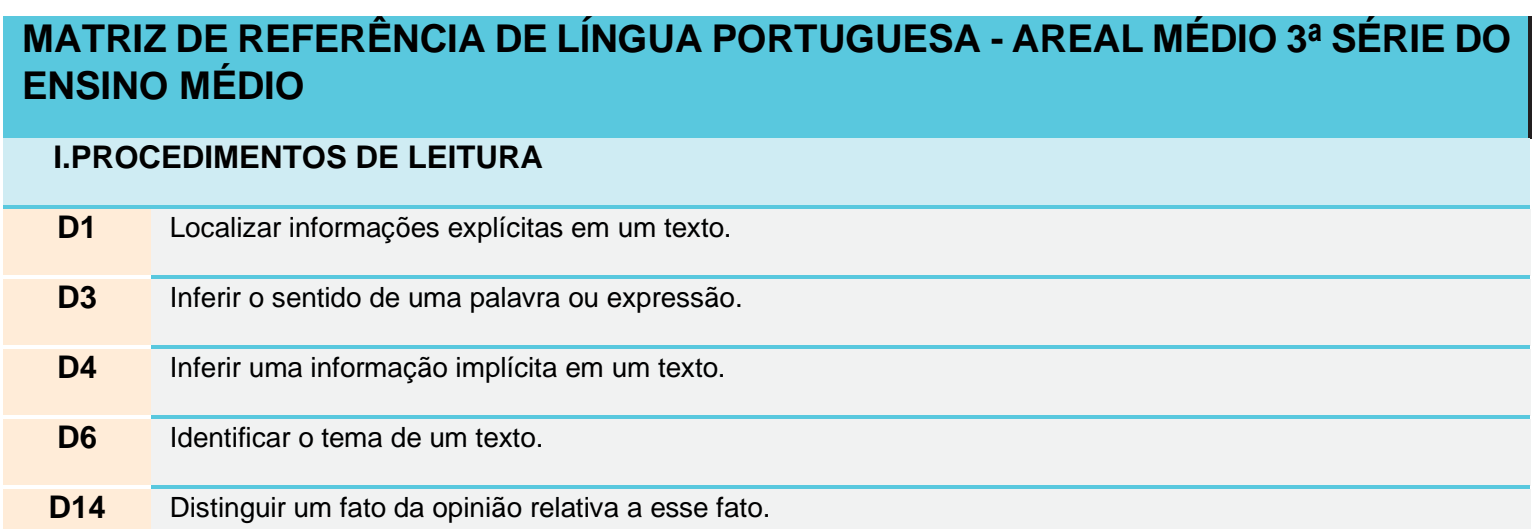

\section{IMPLICAÇÕES DO SUPORTE, DO GÊNERO E/OU DO ENUNCIADOR NA COMPREENSÃO DO TEXTO}

D5 Interpretar texto com auxílio de material gráfico diverso (propagandas, quadrinhos, foto, etc.).

D12 Identificar a finalidade de textos de diferentes gêneros.

\section{RELAÇÃO ENTRE TEXTOS}

D20 Reconhecer diferentes formas de tratar uma informação na comparação de textos que tratam do mesmo tema, em função das condições em que ele foi produzido e daquelas em que será recebido.

D21 Reconhecer posições distintas entre duas ou mais opiniões relativas ao mesmo fato ou ao mesmo tema.

\section{COERÊNCIA E COESÃO NO PROCESSAMENTO DO TEXTO}

D2 Estabelecer relações entre partes de um texto, identificando repetições ou substituições que contribuem para a continuidade de um texto.

D7 Identificar a tese de um texto.

D8 Estabelecer relação entre a tese e os argumentos oferecidos para sustentá-la.

D9 Diferenciar as partes principais das secundárias em um texto.

D10 Identificar o conflito gerador do enredo e os elementos que constroem a narrativa.

D11 Estabelecer relação causa/consequência entre partes e elementos do texto.

D15 Estabelecer relações lógico-discursivas presentes no texto, marcadas por conjunções, advérbios, etc.

\section{RELAÇÕES ENTRE RECURSOS EXPRESSIVOS E EFEITOS DE SENTIDO}

D16 Identificar efeitos de ironia ou humor em textos variados.

D17 Reconhecer o efeito de sentido decorrente do uso da pontuação e de outras notações.

D18 Reconhecer o efeito de sentido decorrente da escolha de uma determinada palavra ou expressão.

D19 Reconhecer o efeito de sentido decorrente da exploração de recursos ortográficos e/ou morfossintáticos.

\section{VARIAÇÃO LINGUÍSTICA}

D13 Identificar as marcas linguísticas que evidenciam o locutor e o interlocutor de um texto. 